\title{
Evaluation of the mechanical integrity of a concrete surface by means of combined destructive methods
}

\author{
L. Courard \\ GeMMe Building Materials, ArGEnCo Department, University of Liège, Belgique \\ B. Bissonnette \\ CRIB, Civil Engineering Department, Laval University, Québec (QC), Canada
}

A. Vaysburd
Vaycon Consulting, Baltimore, MD, U.S.A.

A. Garbacz

Warsaw University of Technology, Poland

\begin{abstract}
As a good bond between the repair and the old concrete is required, the soundness of the prepared surface has to be carefully assessed. This paper presents the results of an investigation intended to assess and compare quantitatively different test methods, namely the rebound hammer and the pull-off test, to evaluate superficial mechanical integrity of a prepared substrate. Although it does not yield a precise evaluation of compressive strength, the rebound hammer test is recognized as a useful tool for performing quick surveys to assess concrete uniformity. The pull-off test is very well correlated with the splitting-tensile test, but it is not suited for vertical and overhead surfaces. It appears from the results generated in this study that the combination rebound hammer / pull-off test could very well fill the needs for the evaluation of prepared horizontal surfaces.
\end{abstract}

\section{INTRODUCTION}

As part of the concrete repair process, in order to promote optimal adhesion of the repair material, the concrete substrate must be prepared to yield a rough surface that is free from defects and contaminants (Bissonnette et al. 2006; Courard et al. 2009). Depending on the technique being used, the concrete removal operation can be harmful to the residual concrete substrate. Whenever bond is key to the success of a repair, the soundness of the prepared surface should be assessed after surface preparation (Vaysburd et al. 2000; Garbacz et al. 2005). This issue could become even more critical than the condition evaluation carried out before undertaking the repair project (Courard et al. 2012).

Although the effect of substrate condition on bond is widely recognized (Silfwerbrand 1990; Courard et al. 2011), there is still no standard method intended for characterizing the integrity of a concrete substrate after concrete removal. For one, Belgian guidelines (2007) explicitly recommend performing a pull off test (EN1542, 1999) directly on the substrate, especially if doubt exists about the quality of surface preparation; a minimum value of $2 \mathrm{MPa}$ is usually recommended. This must be seen as a guiding value. For low strength concrete, a lower value could be specified.

An experimental program has been conducted by the authors (Bissonnette et al. 2004) to evaluate the influence of various parameters on the measured cohesion of a concrete surface by means of pull off test. The test method shows good potential for a sound quantitative evaluation of a concrete surface mechani- cal integrity prior to repair, provided that the test parameters are selected properly.

Test location and interpretation of test results (Bungey 2000) must consider the possible variations of material properties within structural members and differences between in-situ and standard specimen strengths. The proper testing layout actually depends on whether it is intended to determine average values for a member (for specification compliance) or to assess the substrate condition in critical areas (for structural adequacy assessment). Furthermore, the number of test locations would vary with the objectives of the test and the expected level of confidence for the overall strength estimates. Typically, between 5 and 8 locations are tested.

This paper presents the results of an investigation intended to assess and compare quantitatively different test methods, namely the rebound hammer and the pull off test, to evaluate the integrity of a substrate after concrete removal operations.

\section{TEST METHODS AND MATERIALS}

\subsection{Schmidt rebound hammer (ASTM C 805 and) EN 12504-2 determination of rebound number}

Due to its simplicity of use and low cost, the rebound hammer is a most widely used device for nondestructive testing of concrete (Figure 1). It operates as follows: a spring-loaded hammer impacts, with a given amount of energy, a steel plunger in contact with the concrete surface, and the distance that the hammer rebounds is recorded. The rebound value is primarily 
influenced by the elastic modulus and strength of the concrete near the surface (Carino 2003). While the test may be simple to perform, the relationship between measured rebound number and in-place concrete strength is sensitive to a number of parameters. In particular, the results are influenced by the moisture condition, carbonation and surface texture of the concrete, as well as hammer inclination (Courard et al. 2011; Carino 2003). Since the plunger's rebound depends on the energy being restituted from the substrate, it is expected that incidence of bruising and cracking in the surface layer will reflect in the recorded values. Although the evaluation of strength is not an issue in the present study, the test results are expressed in terms of strength.

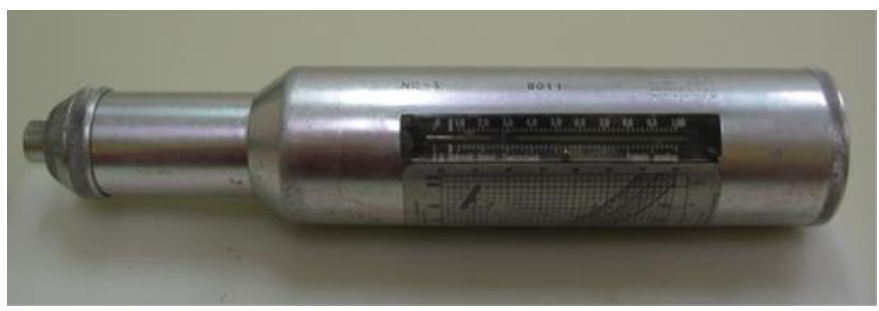

Figure 1. The Schmidt rebound hammer

\subsection{Pull off test (EN 1542-4,)}

The pull off test is commonly used to assess the adhesion of repair systems to concrete.

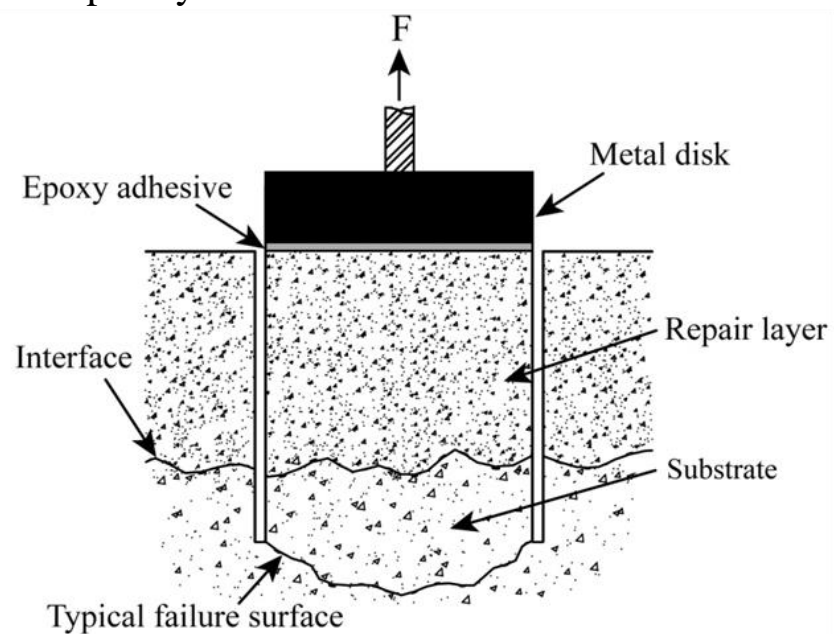

Figure 2. Pull off test

It measures the direct tensile force required to pull off a metallic disk, together with a layer of concrete, from the surface to which it has been epoxy-glued (Figure 2).

The pull off test can also be used to evaluate the cohesion and integrity of a concrete surface to be repaired (Bungey et al. 2001; Hindo 1990; Emberson et al. 1990; Austin et al. 1995). An experimental program was conducted in a previous study (Bissonnette et al. 2004) to evaluate the influence of various test parameters - metal disk thickness and diameter, core drilling depth, loading rate, adhesive type and thickness, and number of tests - to measure the cohesion of a reference concrete surface. A statistical results analysis revealed that disk diameter and core-drilling depth are the most significant parameters, presumably with threshold values (Figure 2), which actually depend on the maximum aggregate size.

In order to yield low standard deviation and satisfactory level of confidence in the results (maximum coefficient of variation of $12 \%$ ), a minimum of 5 tests is recommended. Other authors (Bungey 2000) recommend a minimum of 6 pull off tests in a specific area to be assessed.

It was proved that up to a certain misalignment limit angle (about $5^{\circ}$ ), load and coring misalignments were not found to yield significantly value of pull-off strength (Courard et al., 2014).

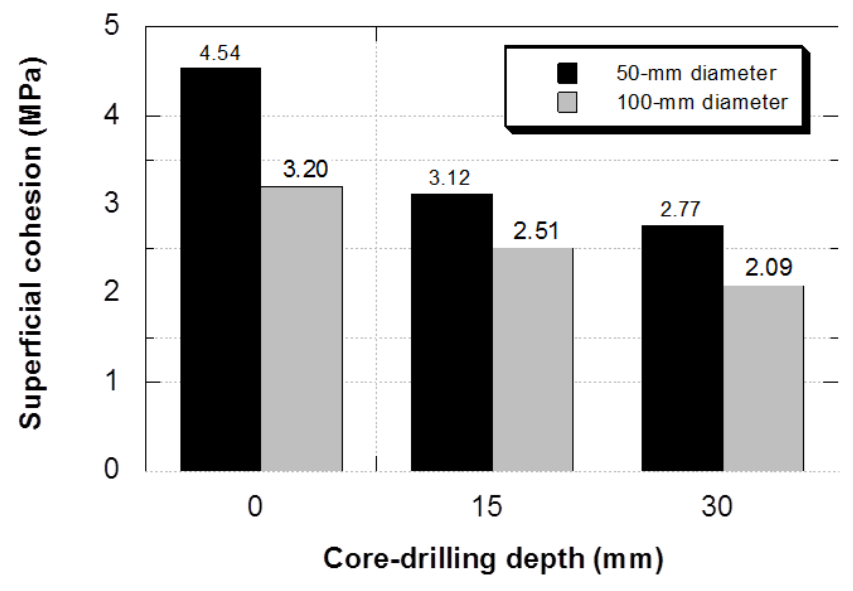

Figure 3. Effects of core-drilling depth and metal disk diameter on surface concrete cohesion (loading rate $<0.05 \mathrm{MPa} / \mathrm{s}$ )

After testing, and depending on the failure mode or value, concrete integrity may need to be assessed further to examine the presence of cracks near the failure surface (mostly parallel to the surface) as a result of surface preparation operations (Bissonnette et al. 2006).

\subsection{Materials}

Experiments have first been performed on untreated concrete surfaces in order to study the significance and sensitivity of test parameters. Then, test series intended to evaluate the cohesion of concrete after various surface treatments were carried out.

Slab test specimens were cast using concrete with 0.40 and 0.48 water/cement ratios, respectively. The former was made using $10-\mathrm{mm}$ crushed granite as coarse aggregates, while the latter used $20-\mathrm{mm}$ aggregates from the same source. Table 1 presents the concrete mixture designs, which had been used as reference materials in other related research projects devoted to repair and rehabilitation issues.

Three concrete batches were prepared for the fabrication of 13 concrete slabs. Two different slab configurations were cast: type $\mathrm{S} 1(500 \times 500 \times 90 \mathrm{~mm})$ and type $S 2(730 \times 730 \times 90 \mathrm{~mm})$. After casting, the slabs 
were covered with wet burlap and a polyethylene sheet for 48 hours. They were then stored in the laboratory at $23{ }^{\circ} \mathrm{C}$ and $50-70 \% \mathrm{RH}$ for 26 days. A relatively good quality of concrete was obtained due to compaction and low w/c ratio: an even higher w/c ratio (S2 vs $\mathrm{S} 1)$ but smaller aggregates offered a good resistance to splitting.

Table 1. Concrete mixture composition and properties

\begin{tabular}{lll}
\hline Mixture design & $\mathrm{S} 1$ & $\mathrm{~S} 2$ \\
\hline Cement CSA type $10\left(\mathrm{~kg} / \mathrm{m}^{3}\right)$ & 384 & 383 \\
Water $\left(1 / \mathrm{m}^{3}\right)$ & 156 & 187 \\
Sand $\left(\mathrm{kg} / \mathrm{m}^{3}\right)$ & 736 & 734 \\
Coarse aggregate $10 \mathrm{~mm}\left(\mathrm{~kg} / \mathrm{m}^{3}\right)$ & - & 916 \\
Coarse aggregate $20 \mathrm{~mm}\left(\mathrm{~kg} / \mathrm{m}^{3}\right)$ & 918 & - \\
Air-entraining $\left(\mathrm{ml} / \mathrm{m}^{3}\right)$ & 78 & 76 \\
Superplasticizer $\left(\mathrm{ml} / \mathrm{m}^{3}\right)$ & 980 & 1269 \\
W/C & 0.40 & 0.48 \\
\hline Slump $(\mathrm{mm})$ & 145 & 75 \\
Compressive strength $(\mathrm{MPa})$ & 32.3 & 46 \\
Splitting tensile strength $(\mathrm{MPa})$ & 3.3 & 4.0 \\
\hline
\end{tabular}

\section{EXPERIMENTAL PROGRAM}

\subsection{Rebound hammer test}

The rebound hammer tests were performed on cast surfaces, before any treatment. To estimate the required number of data for statistical significance, a large number of tests were carried out. Based on the results summarized in Table 2, it seems that the average compressive strength estimated with the rebound hammer is not significantly influenced by the number of tests, at least beyond 25 replicas. It thus appears that 25 tests are sufficient (but also necessary) for the surface investigated.

The rebound hammer results obtained for all concrete slabs are presented in Figure 4. The differences between $\mathrm{S} 1-3$ and $\mathrm{S} 1-3 *$ appear to be mostly related to the nature of the support provided underneath the test slabs, either continuous (wooden platform) or discontinuous (2 wood lumbers), which offer different rigidities.

Table 2. Schmidt rebound hammer test results: influence of the number of tests performed upon statistical parameters (S2 slab specimens)

\begin{tabular}{lllllll}
\hline $\begin{array}{l}\text { Statistical } \\
\text { parameter }\end{array}$ & \multicolumn{3}{c}{$\begin{array}{l}\text { S2-5 } \\
\text { slab }\end{array}$} & \multicolumn{3}{c}{$\begin{array}{l}\text { S2-6 } \\
\text { slab }\end{array}$} \\
\hline & 61 & 36 & 25 & 61 & 36 & 25 \\
\hline $\begin{array}{l}\text { Ave. value } \\
(\mathrm{MPa})\end{array}$ & 32.3 & 32.1 & 32.5 & 30.9 & 30.9 & 30.8 \\
$\begin{array}{l}\text { Coefft. of } \\
\text { var. }(\%)\end{array}$ & 10.1 & 10.8 & 9 & 8.3 & 9.3 & 6.8 \\
\hline
\end{tabular}

Variability, which was evaluated with the coefficient of variation $(\mathrm{CV})$, was lower when the concrete specimen was placed on a continuous support.

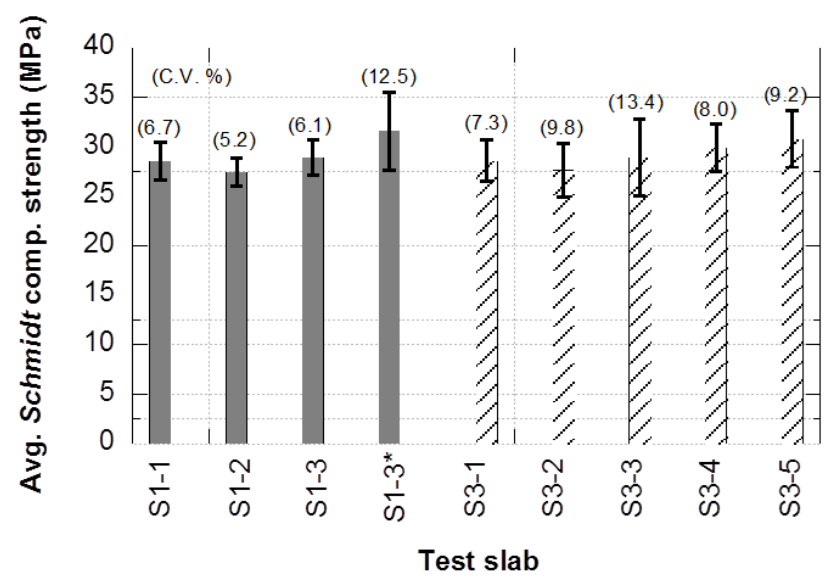

Figure 4. Average compressive strength values estimated from the rebound hammer tests on flat finished slab specimens

\subsection{Pull-off test}

The pull-off tests were performed on the S1- and S2series slabs using a core-drilling depth of $20 \mathrm{~mm}$. The test results are summarized in Table 3 . The aggregate size appears to have a limited influence on cohesion strength and variability. Nonetheless, the location and shape of the failure surface were more variable for the larger size aggregate concrete.

Table 3. Pull off test results (S1- and S2-series test slabs)

\begin{tabular}{lcc}
\hline Test nr. & \multicolumn{2}{c}{ Pull off stress (MPa) } \\
\hline & $\begin{array}{l}\text { S1-series } \\
\text { slabs }\end{array}$ & $\begin{array}{l}\text { S2-series } \\
\text { slabs }\end{array}$ \\
\hline 1 & 3.42 & 3.92 \\
2 & 3.06 & 3.60 \\
3 & 3.35 & 4.19 \\
4 & 3.24 & 4.10 \\
5 & 3.30 & 3.92 \\
6 & 3.30 & 3.67 \\
7 & 3.12 & 4.05 \\
8 & 3.40 & 4.01 \\
\hline Average value & 3.27 & 3.93 \\
Coefficient of Variation $(\%)$ & 3.91 & 5.12 \\
\hline
\end{tabular}

Overall, the recorded values are very close to the corresponding splitting tensile strength data (Table 1). This is consistent with the results of a previous program (Bissonnette et al. 2004), where pull off testing was shown to be an effective technique for evaluating the mechanical integrity of horizontal surfaces after concrete removal. For quality control purposes, an acceptance criterion corresponding to a fraction of the average splitting-tensile strength $\left(f_{s t}\right)$ result could be specified. 


\section{CONCLUSIONS}

Surface preparation is often a critical step in concrete repairs. While it is well acknowledged that the concrete removal operation can induce bruising and cracking in the substrate, there are still no simple practical means available to assess the integrity of a concrete surface. The investigation reported in this paper intended to evaluate different test methods for that purpose: the rebound hammer and the pull off test.

Although the rebound hammer test cannot systematically yield a reliable evaluation of the in-place compressive strength of concrete, it was shown to provide valuable comparative data for detecting superficial defects on a concrete surface. The rebound hammer method is thus recognized as a useful tool for performing quick surveys to assess concrete uniformity and mechanical integrity over substrates.

The pull off test provided results that are very close to the actual splitting-tensile strength of the material. Moreover, it was shown in a previous study (Bissonnette et al. 2006) that it can effectively capture the presence of bruising. Still, it is difficult to perform adequately on vertical or overhead surfaces and, in practice; its use is essentially limited to horizontal surfaces.

Finally, it appears from the results generated in this study that the combination rebound hammer / pull off tests can fulfill the needs for the evaluation of horizontal surfaces. For quality control purposes, acceptance criteria could be specified for both the hammer soundings (ex. C.V. $<20 \%$ ) and cohesion strength test results (ex. pull off test: cohesion strength $>0.75$ fst.

\section{ACKNOWLEDGMENTS}

This project has been financially supported by the Natural Sciences and Engineering Research Council of Canada (NSERC), the Québec FQRNT Research Fund and the industrial partners of the Industrial Chair on Durable Repair and Optimized Maintenance of Concrete Infrastructures at Laval University (BASF Building Systems, City of Montreal, City of Québec, Euclid, Hydro-Québec, King Packaged Materials, Lafarge, Ministry of Transportation of Québec, StLawrence Cement, W.R. Grace \& Co. Support was also provided by the Belgium (Wallonia Brussels International) and Quebec governments through the Wallonie-Bruxelles-Québec Scientific Cooperation Program as well as Belgium - Poland (MNiSW) Scientific Cooperation Program.

\section{REFERENCES}

Austin, S.; Robins, P.; and Pan, Y., "Tensile Bond Testing of Concrete Repair," Materials and Structures, V. 28, No. 179, 1995, pp. 249-259.

Belgian Construction Certification Association, "Technical Prescriptions for Concrete Repair Mortars," Belgian Guidelines PTV 563, Brussels, Belgium, 2007

Bissonnette, B.; Courard, L.; Vaysburd A.; and Bélair, N., "Concrete Removal Techniques: Influence on Residual Cracking and Bond Strength," Concrete International, V. 28, No. 12, 2006, pp. 49-55.

Bissonnette, B., and Courard, L., "Pull Off Test for the Evaluation of the Superficial Cohesion of Concrete Substrates in Repair Works: Analysis of the Test Parameters (in French)," Materials and Structures, V. 37, 2004, pp. 342-350.

Bungey, J.H., "Assessment of In-Situ Concrete Strength: Overview of Test Procedures," University of Liverpool, 2000.

Bungey, J.H., and Soutsos, M.N., "Reliability of PartiallyDestructive Tests to Assess the Strength of Concrete on Site," Construction and Building Materials, V. 15, 2001, pp. 81-92.

Carino, N.J., "Non Destructive Test Methods to Evaluate Concrete Structures," Sixth CANMET/ACI International Conference on the Durability of Concrete, Special Seminar, Thessaloniki, Greece, 2003, 75 pp.

Courard, L.; Bissonnette, B.; Garbacz A., Vaysburd A.; von Fay K.,; Moczulski G., Morency M., "Effect of Misalignment on Pulloff Test Results: Numerical and Experimental Assessments", ACI Materials Journal, 2014, 111 (1-6).

Courard L.; Bissonnette B.; Vaysburd A.; Belair N.; Lebeau F., "Comparison of destructive methods to appraise the mechanical integrity of a concrete surface". Concrete Repair Bulletin 25(4) (July-August 2012), 22-30.

Courard, L.; Michel, F.; Schwall, D.; Van der Wielen, A.; Garbacz, A.; Piotrowski, T., Perez, F.; and Bissonnette, B., "Surfology: Concrete Substrate Evaluation prior to Repair," Materials Characterization: Computational Methods and Experiments IV, A. Mammoli and C.A. Brebbia eds., Wessex Institute of Technology Press, The New Forest (U.K.), June 17-19, 2009, pp. 407-416.

Courard, L.; Bissonnette, B.; and Trevino M., "Condition Evaluation of the Existing Structure prior to Overlay," Bonded cement-based material overlays for the repair, the lining or the strengthening of slabs or pavements, Report of RILEM TC 193-RLS, 2011, pp. 17-50.

Emberson, N.K., and Mays, G.C., "Significance of Property Mismatch in the Patch Repair of Structural Concrete Part 1: Properties of Repair Systems," Magazine of Concrete Research, V. 42, No. 152, 1990, pp. 147-160.

EN 1542 CEN European Committee for Standardization, "Products and systems for the protection and repair of concrete structures - Test methods - Measurement of bond strength by pull-off', Brussels, Belgium, 1999.

Garbacz, A.; Gorka, M.; and Courard L., "Effect of Concrete Surface Treatment on Adhesion in Repair Systems," Magazine of Concrete Research, V. 57, No. 1, 2005, pp. 49-60.

Hindo, K.L., "In-Place Bond Testing and Surface Preparation of Concrete," Concrete International, V. 12, No. 4, 1990, pp. 46-48.

Silfwerbrand, J., "Improving Concrete Bond in Repaired Bridge Decks," Concrete International, V. 12, No. 9, 1990, pp. 6166.

Vaysburd, A. M., and Emmons, P.H., "How to Make Today's Repairs Durable for Tomorrow - Corrosion Protection in Concrete Repair," Construction and Building Materials, V. 14, No. 4, 2000, pp. 189-197. 